NBER WORKING PAPER SERIES

\title{
INFORMATION, TECHNOLOGY AND INFORMATION WORKER PRODUCTIVITY: TASK LEVEL EVIDENCE
}

\author{
Sinan Aral \\ Erik Brynjolfsson \\ Marshall Van Alstyne \\ Working Paper 13172 \\ http://www.nber.org/papers/w13172
}

\author{
NATIONAL BUREAU OF ECONOMIC RESEARCH \\ 1050 Massachusetts Avenue \\ Cambridge, MA 02138 \\ June 2007
}

We are grateful to the National Science Foundation (Career Award IIS-9876233 and grant IIS-0085725), Intel Corporation, the Marvin Bower Fellowship, and the MIT Center for Digital Business for generous funding. We thank Abraham Evans-El, Jia Fazio, Saba Gul, Davy Kim, Jennifer Kwon and Jun Zhang for their remarkable and tireless research assistance, and Julie Hilden, and seminar participants at the NBER, NYU, MIT, Georgia Tech, the Workshop on Information Systems and Economics for valuable comments. The views expressed herein are those of the author(s) and do not necessarily reflect the views of the National Bureau of Economic Research.

(C) 2007 by Sinan Aral, Erik Brynjolfsson, and Marshall Van Alstyne. All rights reserved. Short sections of text, not to exceed two paragraphs, may be quoted without explicit permission provided that full credit, including $\odot$ notice, is given to the source. 
Information, Technology and Information Worker Productivity: Task Level Evidence

Sinan Aral, Erik Brynjolfsson, and Marshall Van Alstyne

NBER Working Paper No. 13172

June 2007

JEL No. D2,D8,J44,L8,M0,O30

\begin{abstract}
$\underline{\text { ABSTRACT }}$
In an effort to reveal the fine-grained relationships between IT use, patterns of information flows, and individual information-worker productivity, we study task level practices at a midsize executive recruiting firm. We analyze both project-level and individual-level performance using: (1) detailed accounting data on revenues, compensation, project completion rates, and team membership for over 1300 projects spanning 5 years, (2) direct observation of over 125,000 email messages over a period of 10 months by individual workers, and (3) data on a matched set of the same workers' self-reported IT skills, IT use and information sharing. These detailed data permit us to econometrically evaluate a multistage model of production and interaction activities at the firm, and to analyze the relationships among key technologies, work practices, and output. We find that (a) IT use is positively correlated with non-linear drivers of productivity; (b) the structure and size of workers' communication networks are highly correlated with performance; (c) an inverted-U shaped relationship exists between multitasking and productivity such that, beyond an optimum, more multitasking is associated with declining project completion rates and revenue generation; and (d) asynchronous information seeking such as email and database use promotes multitasking while synchronous information seeking over the phone shows a negative correlation. Overall, these data show statistically significant relationships among technology use, social networks, completed projects, and revenues for project-based information workers. Results are consistent with simple models of queuing and multitasking and these methods can be replicated in other settings, suggesting new frontiers for IT value and social network research.
\end{abstract}

Sinan Aral

44 West 4th Street Room 8-81

New York, NY 10012

sinana@mit.edu

Erik Brynjolfsson

MIT Sloan School of Management

E53-313

50 Memorial Drive

Cambridge, MA 02142

and NBER

erikb@mit.edu
Marshall Van Alstyne

Boston University

595 Commonwealth Ave, Room 634

Boston, MA 02215

mva@bu.edu 
"In the physical sciences, when errors of measurement and other noise are found to be of the same order of magnitude as the phenomena under study, the response is not to try to squeeze more information out of the data by statistical means; it is instead to find techniques for observing the phenomena at a higher level of resolution. The corresponding strategy for [social science] is obvious: to secure new kinds of data at the micro level."

-- Herbert Simon

\section{Introduction}

Information workers now account for as much as $70 \%$ of the U.S. labor force and contribute over $60 \%$ of the total valued added in the U.S. economy (Apte \& Nath 2004). Ironically, as more and more workers focus on processing information, researchers have less and less information about how these workers create value, and managers have greater difficulty measuring, managing and optimizing work. Unlike bushels of wheat or tons of steel, the real output of most information workers is difficult to measure. Counting meetings attended or memos filed is not closely linked to the value these activities create. But, as the information content of work increases, the role of information becomes increasingly central to our understanding of the performance of individuals, groups and organizations. This paper explores the relationship between information, technology and information worker productivity, using detailed empirical evidence to examine how IT use and information seeking habits affect individual level output. Our findings not only uncover relationships among IT use and skill, communication behaviors, social networks, and productivity, they shed light on the underlying mechanisms that drive performance.

By studying a single industry in depth, Ichniowski, Shaw and Prennushi (1997) were able to specify a precise blue collar production function for steel finishing lines, and measure the effects of particular work practices and technologies on productivity. The corresponding strategy for comprehending information work is clear: to secure task-level data for a specific group of information workers. Our study focuses on executive recruiters, or "head hunters," whose primary work involves filling clients' job openings. Output is precisely observable in this setting because accounting data provide complete and detailed records of project-level and individual-level revenues, the number of projects completed, project duration, the number of simultaneous projects, and project and individual-level characteristics. With the company's 
and employees' cooperation, we also monitored email usage and conducted detailed surveys and interviews focusing on activities, skills, behaviors, and perceptions relevant to information work.

Our IT variables focus on the use of technology, not merely its presence, and include direct, message-level observation of communications volume, the size and shape of email contact networks, professed ability to use database technology, and relative time spent on various information seeking tasks. When combined with interviews and visits, these data enabled us to specify and estimate several equations relating technology, skill, social network structure, worker characteristics, task completion and revenue generation. Narrowly focusing on one industry allowed us to precisely define the white collar production process, and our concentrated data collection from one firm eliminates many sources of heterogeneity that confound productivity estimation at more aggregate levels of analysis.

Our results demonstrate that information flows and IT use do in fact predict significantly higher levels of economic productivity. Employees that use databases more also conduct more work simultaneously and finish projects faster. Heavier database users generate more revenue for the firm per unit time. But our analyses at the task level, designed to unpack the processes driving performance, also reveal some counterintuitive results. We find that individuals occupying central brokerage positions in the firm's communication network, who arguably have more structurally efficient access to novel information, are not necessarily more efficient per project. Instead, their higher levels of productivity are driven by higher capacities to multitask across simultaneous projects. Richer communications structure predicts greater multitasking, and multitasking drives productivity, demonstrating that technology use not only speeds work, it enables new ways of working that can make workers more productive. Our results reveal a substantial program of correspondence among information, technology and output, and motivate new questions regarding the tradeoffs between multitasking and the speed of work, and how information affects intermediate production processes in white collar work.

\section{Theory and Literature}

\subsection{Information, Technology and Productivity}


Historically, technological revolutions have triggered sustained increases in productivity (David 1990). In the information age, new technologies, new ways of working, and an increasing availability of information could significantly affect productivity growth, and specifically, the productivity of workers in information-intensive industries. From 1995 to 2005, annual productivity growth in the U.S. averaged more than 3\%, more than doubling the rate in the preceding two decades. A growing body of literature links these productivity gains to IT-intensive industries and firms. Studies of the relationship between IT and economic productivity have examined empirical evidence at the country (e.g. Dewan \& Kraemer 2000), industry (e.g. Jorgenson \& Stiroh 2000), and firm (e.g. Brynjolfsson \& Hitt 1996) levels, demonstrating a convincing positive relationship across distinct measures (Brynjolfsson \& Hitt 2000, Bharadwaj et. al. 1999). A handful of task-level studies of IT and productivity have been conducted in recent years (e.g. Bartel, Ichniowski \& Shaw forthcoming, Ichniowski, Shaw \& Prennushi 1997, Barua, Kreibel \& Mukhopadhyay 1994, Mukhopadhyay 1997, McAfee 2002). However, most of these studies focus on the manufacturing sector and measure outputs pertaining to the production or distribution of physical goods, leaving a number of important questions unanswered. For example, the mechanisms by which IT affects productivity are not well understood and the output and production function for information workers such as managers, consultants, researchers, marketers, lawyers and accountants remain poorly modeled and measured.

Information technologies may be particularly important for the productivity of information workers not only because IT enables information workers to search for, retrieve, analyze and store information, but because technologies such as email enable new forms of work organization and communication that are increasingly asynchronous, geographically dispersed and sustained over longer periods of the day (e.g. Hinds \& Kiesler 2002). As information work represents a growing proportion of the GDP, and is increasingly leveraged with IT, understanding IT and productivity in the context of information work is especially important. Accordingly, we seek to explore a new frontier for IT productivity research by using detailed task-level data to open the black box of the firm and understand how information and technology affect information work at the level of individual workers. 


\subsection{Information and Productivity}

Two broad theoretical arguments contend that information should enable increased productivity (Buckley \& Van Alstyne 2004). First, reductions in uncertainty can improve resource allocations and decision making, and reduce delay costs (Cyert \& March 1963, Galbraith 1973). In our context, more precise or accurate information about the candidate pool can reduce time wasted interviewing candidates unsuitable for a given executive search. Uncertainty exists for recruiters when information is inaccurate, out of date, hard to find, or imprecise, and decisions based on faulty or incomplete information make filling positions more difficult. Precise information also tempers risk aversion, enabling actors to make appropriate decisions faster (Arrow 1962, Stiglitz 2000). Reductions in uncertainty help recruiters place the right candidates in front of the right clients at the right time, increasing the likelihood of concluding searches faster and, therefore, increasing contract execution per unit time. Second, sharing procedural information or know-how can improve the efficiency with which employees handle recurrent search problems. Knowledge sharing on difficult recurring situations improves effectiveness (Szulanski 1996), although at times complex knowledge may be tied to particular contexts (Von Hippel 1998) or difficult to transfer (Hansen 1999). In interviews, executive recruiters report learning to deal with difficult situations through communication with peers.

\subsection{Social Structure, Information Flows and Information Advantage}

If information influences productivity, its distribution and diffusion patterns are likely to affect the relative productivity of individuals and groups. Over several decades, social network research has examined how information can alter competitive dynamics, access to resources, awareness of opportunity, negotiating leverage, teamwork and ultimately performance. For example, individuals whose networks contain many structural holes may derive information and control benefits from the lack of connectivity among people in their network (Burt 1992), with their access to more non-redundant information making them more likely to receive early promotion (Burt 1992), enjoy greater career mobility (Podolny \& Baron 1997), and adapt more quickly to change (Gargiulo \& Benassi 2000). 
Others argue that cohesion is more important for group performance than structural diversity because information in cohesive groups is more complete, fostering stronger norms of trust, reciprocity and familiarity, and improving the precision with which actors understand their environments (Coleman 1988). Reagans \& Zuckerman (2001) show that cohesion within and structural holes across groups improve the innovation output of R\&D teams. Podolny \& Baron (1997) find that while cohesive ties are beneficial in 'buy-in' networks and for those contacts that have control over the fate of employees, structural holes are important in advice and information networks. Hansen (2002) finds that business units with shorter path lengths to other units that possess related knowledge finish projects faster, and that advice giving and advice receiving ties have differential impacts on project duration.

We seek to complement and extend this body of work by addressing an understudied yet fundamental question at the heart of the relationship between social network structure and economic performance: Are individuals and groups in favorable structural positions actually more productive? By addressing a performance dimension whose evaluation is removed from social influence, we avoid the endogeneity of socially derived peer performance evaluation apparent in a great deal of social network research.

\section{Background and Data}

\subsection{Research Setting: The Role of Information and Technology}

We studied a medium-sized executive recruiting firm over five years, with fourteen regional offices throughout the U.S. The employees occupy three basic positions - partner, consultant and researcher, and conduct their 'searches' in teams. Our interviews indicate that the process for securing and executing a contract is relatively standard: A partner secures a contract with a client and assembles a project team (team size mean $=1.9, \min =1, \max =5)$. The team then establishes a universe of potential candidates including those in similar positions at other firms and those drawn from the firm's internal database of resumes and other leads. These candidates are vetted on the basis of perceived quality, their match with the job description and other factors. After conducting initial due diligence, the team chooses a subset of candidates for internal interviews, approximately six of which are forwarded to the client along with detailed background information, notes and a formal report of the team's due diligence. The team 
then facilitates the client's interviews with each candidate, and the client, if satisfied with the pool, makes offers to one or more candidates. A contract is considered complete when a candidate accepts an offer.

The core of executive recruiters' work involves retrieving and understanding clients' requirements and matching candidates to those requirements. ${ }^{1}$ This matching process is information-intensive and requires activities geared toward assembling, analyzing, and making decisions based on information gathered from various sources including team members, other firm employees, contacts outside the firm, and data on potential candidates in the internal proprietary database, external proprietary databases, and public sources of information.

Recruiters earn revenue for the firm by filling vacancies, rather than billing hourly. Therefore, the speed with which vacancies are filled is an important intermediate measure of workers' productivity. Contract completion implies that the search team has met the client's minimum thresholds of candidate fit and quality, and given controls for differences across characteristics of contracts (e.g. job type, location), project duration (in addition to the real dollar output value of each contract) can be interpreted as a quality controlled measure of team and worker productivity.

Interviews with the CIO and other employees indicate that the firm uses IT in essentially two ways: 1) as a communication vehicle (e.g. phone, voicemail, and email) and 2) as a central repository of information and knowledge about ongoing projects, potential candidates and internal task coordination. Both of these functions facilitate the information exchanges teams require to systematically assemble, analyze, codify and share knowledge about candidates and clients.

The firm pays to use external databases and has its own proprietary Executive Search System (ESS), built from an off-the-shelf relational database. The ESS not only provides a repository of information on current and past projects, the firm's own employees (e.g. contact information, areas of expertise, work history and current assignments), clients, and potential candidates (e.g. resumes, prior due diligence, and notes or "work ups" on their previous jobs); it also helps employees coordinate and manage depend-

\footnotetext{
1 "Client" refers to a firm seeking to hire one or more executives; "candidate" refers to a potential hire; and "recruiter" refers to someone expert in locating, vetting, and placing candidates.
} 
encies across projects. For example, when searching for potential candidates, employees must honor contractual obligations that prevent poaching employees of past clients for one year. The ESS maintains an up-to-date record of candidates that are 'frozen' due to prior client obligations and employees use this information to coordinate contractual obligations across projects while selecting potential candidates.

\subsection{Data}

Data for this study include three separate data sets from the firm and one from outside the firm. The first is exact internal accounting records of: (i) revenues generated by individual recruiters, (ii) contract start and stop dates, (iii) projects handled simultaneously by each recruiter, (iv) labor costs and compensation, (v) project team composition, (vi) job levels of recruiters, and (vii) job levels of placed candidates. Accounting data cover the period 2001-2005. These provide excellent output measures that can also be normalized for quality.

The second set of data covers 10 months of complete email history captured from the corporate mail server during two equal periods from October 1, 2002 to March 1, 2003, and from October 1, 2003 to March 1, 2004. Email data has the potential to overcome bias in survey respondent recall of their social networks (see the 'BKS Studies': e.g. Bernard et. al 1981) by objectively recording who is communicating with whom and when. However, it is not without its own limitations as a source of data. We therefore took great care in collecting and analyzing our social network data. We wrote and developed capture software specific to this project and took multiple steps to maximize data integrity and levels of participation. New code was tested at Microsoft Research Labs for server load, accuracy and completeness of message capture, and security exposure. To account for differences in user deletion patterns, we set administrative controls to prevent data expunging for 24 hours (Van Alstyne \& Zhang, 2003). The project went through nine months of human subjects review prior to launch and content was masked using cryptographic techniques to preserve individual privacy. Spam messages were excluded by eliminating external contacts who did not receive at least one message from someone inside the firm. Participants received 
$\$ 100$ in exchange for permitting use of their data, resulting in $87 \%$ coverage of recruiters eligible to participate and more than 125,000 email messages captured. ${ }^{2}$

The third data set contains survey responses on information-seeking behaviors, perceptions, experience, education, human factors, and time allocation. Survey questions were generated from a review of relevant literature and interviews with recruiters. Experts in survey methods at the Inter-University Consortium for Political and Social Science Research vetted the survey instrument, which was then pretested for comprehension and ease-of-use. Individual participants received $\$ 25$ for completed surveys and participation exceeded $85 \%$.

The fourth data set involves independent controls for placement cities to normalize for project difficulty and will be described below. Together, these data provide a desktop-level view of information flows and IT use that we matched to precise measures of individual performance. Aggregating individual revenues also provides a complete picture of firm-level revenues.

Following our qualitative assessment of the role of IT in the firm's production process, we concentrated our measurement of IT around (a) the intensity and skill with which employees used the ESS system, and (b) the frequency of use of different modes of communication in maintaining contacts and seeking information. In measuring ESS skill, we asked respondents to evaluate (i) their personal effectiveness using the ESS system and (ii) their ability to find, add, and modify the records it contains. As these two factors were highly correlated (Spearman $\left.=.88^{* * *}, \alpha=.94\right)$, we combined them into a single measure. To measure ESS use intensity, we asked respondents to estimate the proportion of time they spent gathering information from the ESS and external databases in order to perform their work. Finally, we asked respondents to estimate the number of people they communicated with in a typical day face-toface, over the phone, and over email. ${ }^{3}$

\footnotetext{
${ }^{2} F$-tests comparing performance levels of those who opted out with those who remained did not show statistically significant differences. $F$ (Sig): Revenue02 2.295 (.136), Compensation02 .837 (.365), Multitasking02 386 (.538).

${ }^{3}$ As we also have an objective measure of this value, we assessed the accuracy of survey responses. Respondents reported a mean number of email contacts equal to 28.1, while the email data revealed a mean of 34.8 (Individual mean email contacts $=$ 28.1 , team mean $=20.1$ ). We could not reject the hypothesis that the difference between these means was zero at the $95 \%$ level.
} 
To measure information flows, we constructed variables for both the levels and structure of email traffic. Since teams at our research site are small - between one and five people - we focus on the global network structure of teams, rather than on their internal structure. Measures of the level of email traffic count the total number of emails sent and received, individuals' network size, and their in-degree and outdegree, which measure individuals' frequency weighted number of contacts. Measures of communication structure include the 'betweenness centrality' of an individual's email network $B\left(n_{i}\right)$ (Freeman 1979), ${ }^{4}$ which measures the probability that the individual will fall on the shortest path between any two other individuals linked by email communication and the 'constraint' of the network $C_{i}$ (Burt 1992: 55) ${ }^{5}$ which measures the degree to which an individual's contacts are connected to each other (a proxy for the redundancy of contacts):

$$
\begin{gathered}
B\left(n_{i}\right)=\sum_{j<k} g_{j k}\left(n_{i}\right) / g_{j k} ; \\
C_{i}=\sum_{j}\left(p_{i j}+\sum_{q} p_{i q} p_{q j}\right)^{2}, \quad q \neq i, j .
\end{gathered}
$$

We examine degree and betweenness centrality measures as proxies for the likelihood of being privy to a useful piece of strategic information, and structural holes to capture the efficiency with which teams and individuals have access to non-redundant information.
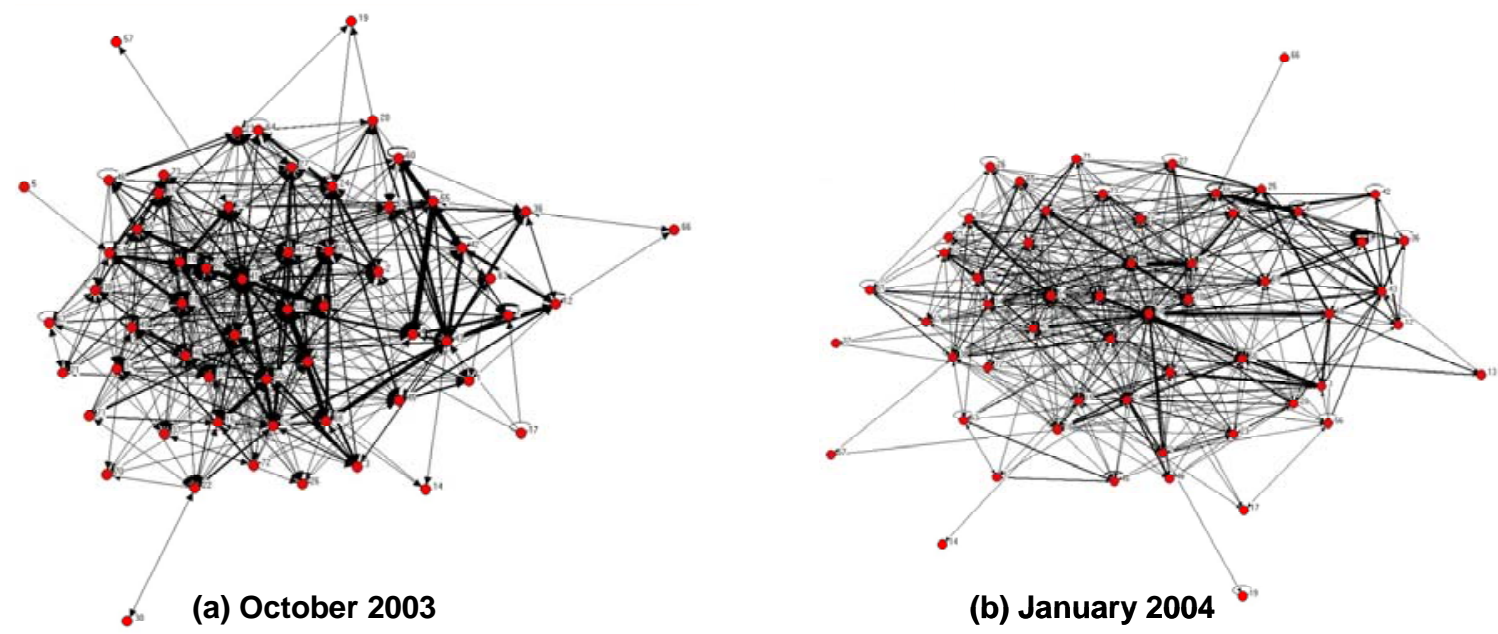

\footnotetext{
${ }^{4}$ Where $g_{j k}$ is the number of geodesic paths linking $j$ and $k$ and $g_{j k}\left(n_{i}\right)$ is the number of geodesic paths linking $j$ and $k$ involving $i$.

${ }^{5}$ Where $p_{i j}+\sum p_{i q} p_{q j}$ measures the proportion of $i$ 's network contacts that directly or indirectly involve $j$ and $C_{i}$ sums this across all of $i$ 's contacts.
} 
Figure 1. We use email messages to map the social network at this firm. Each node represents an individual in our data set, while the thicknesses of the links represent the amount of email traffic between individuals over two four week periods.

We distinguish between incoming and outgoing email to proxy for differences between information seek-

ing and information provision and, in order to control for the overall level of communication, control for the total amount of email in our analyses. Two four week patterns of email traffic are shown in Figure 1 while Table 1 provides descriptive statistics for all variables, and Appendix A provides their descriptions and data sources.

\begin{tabular}{|c|c|c|c|c|c|}
\hline Variable & Obs. & Mean & SD & Min & Max \\
\hline \multicolumn{6}{|l|}{ Project Team Variables } \\
\hline Team Size & 1382 & 1.98 & .60 & 1 & 5 \\
\hline Age & 1372 & 45.07 & 7.77 & 27 & 63 \\
\hline Yrs Education & 1372 & 17.74 & 1.02 & 15 & 20 \\
\hline Industry Experience & 1372 & 14.47 & 7.94 & 1 & 39 \\
\hline Multitasking & 1382 & 8.86 & 2.84 & 1.60 & 18.31 \\
\hline Project Duration (Days) & 1382 & 206.90 & 123.69 & 3 & 981 \\
\hline Project Revenue Value (\$) & 1301 & 56962.5 & 25780.7 & 11666 & 237636 \\
\hline Team Interdependence & 1382 & 1.36 & .749 & .05 & 4.65 \\
\hline Task Routiness & 1382 & 1.18 & .88 & .05 & 4 \\
\hline F2F Contacts & 1382 & 4.20 & 8.68 & 0 & 75 \\
\hline Phone Contacts & 1382 & 15.76 & 10.54 & 1 & 70 \\
\hline Email Contacts & 1382 & 20.14 & 18.46 & 1 & 100 \\
\hline ESS (Database) Skill & 1382 & 3.10 & 1.92 & .12 & 9.30 \\
\hline ESS (Database) Use (\%) & 1382 & 15.79 & 14.45 & 0 & 80 \\
\hline Total Emails & 1382 & 1365.67 & 760.19 & .6 & 3939 \\
\hline Total Emails Sent & 1382 & 667.89 & 393.96 & .3 & 1985 \\
\hline Total Emails Received & 1382 & 697.79 & 378.34 & .3 & 1954 \\
\hline Degree Centrality & 1382 & 1295.23 & 720.24 & 6 & 3584 \\
\hline In Degree & 1382 & 632.66 & 373.01 & .3 & 1804.2 \\
\hline Out Degree & 1382 & 662.56 & 360.04 & .3 & 1854 \\
\hline Network Size & 1382 & 37.80 & 11.90 & .6 & 79.36 \\
\hline Betweenness & 1382 & 37.55 & 26.12 & 0 & 185.69 \\
\hline Constraint (1-Structural Holes) & 1382 & .18 & .07 & .02 & .49 \\
\hline \multicolumn{6}{|l|}{ City Characteristics } \\
\hline Cost of Living & 1187 & 358.65 & 144.49 & 233.60 & 2059.60 \\
\hline Crime per Capita & 1187 & 6262.40 & 2648.76 & 0 & 14603.80 \\
\hline Sunny Days per Annum & 1187 & 212.15 & 33.93 & 23 & 300 \\
\hline Commute Time (Minutes) & 1187 & 20.22 & 5.38 & 9 & 43 \\
\hline \multicolumn{6}{|l|}{ Individual Variables - Daily } \\
\hline Daily Project Output & 104982 & .017 & .017 & 0 & .84 \\
\hline Daily Revenue Output & 100815 & 694.82 & 690.24 & 0 & 3353.35 \\
\hline Multitasking & 104983 & 6.55 & 5.51 & 0 & 28 \\
\hline Share Weighted Multitasking & 104983 & 3.36 & 2.91 & 0 & 14.25 \\
\hline Average Project Duration & 107658 & 212.01 & 158.55 & 0 & 1218.75 \\
\hline
\end{tabular}




\section{Models and Hypotheses}

\subsection{A Production Model of Revenue and Project Output for Executive Recruiting}

A decade ago, moving from aggregate data to more fine grained data at the firm level helped resolve the 'IT productivity paradox.' Explorations at the firm level, however, are still constrained by the granularity of the data and thus can only explain whether IT increases productivity, not how IT increases productivity. Our data allow us to construct a detailed model of the production process of executive recruiters, and to test the impact of IT and information flows on intermediate process metrics and final output measures. We conduct both individual and project-level analyses that examine the specific mechanisms through which IT and information affect the production process of information workers.

As a first step in model development, we took a more traditional approach and examined the relationship between IT and revenues directly. We also evaluated a popular conception of how IT may improve productivity: by increasing the pace of work. There has been much discussion of how IT speeds work activities into the "fast lane" and drives business at "Internet speed." All else being equal, faster completion of projects should lead to more revenues. Indeed, in our exploratory analysis, we did find a positive and statistically significant correlation between IT and revenue. However, to our surprise, we also found that our IT and information flow variables were actually correlated with longer project duration on average (see Table 2).

\begin{tabular}{|c|c|c|c|}
\hline Variables & Model 1 & Model 2 & Model 3 \\
\hline $\begin{array}{l}\text { Dependent } \\
\text { Variable: }\end{array}$ & Revenue & Multitasking & Duration \\
\hline Partner & $\begin{array}{c}354,668.03 * * \\
(101188.43)\end{array}$ & $\begin{array}{l}2.63 \\
(2.06)\end{array}$ & $\begin{array}{c}16.38 \\
(36.72)\end{array}$ \\
\hline Consultant & $\begin{array}{c}420,625.63 * * * \\
(86713.60)\end{array}$ & $\begin{array}{c}2.39 \\
(1.76)\end{array}$ & $\begin{array}{c}20.13 \\
(45.19)\end{array}$ \\
\hline Internal Email & $11,657.50 * * *$ & $.126 * *$ & $1.91 *$ \\
\hline Contacts & (2102.09) & $(.043)$ & $(.987)$ \\
\hline ESS Skill & $\begin{array}{l}326.32 * \\
(194.74)\end{array}$ & $\begin{array}{l}.009 * * \\
(.004)\end{array}$ & $\begin{array}{l}.169 * * \\
(.083)\end{array}$ \\
\hline Controls & $\begin{array}{l}\text { Gender, Education, } \\
\text { Industry Experience }\end{array}$ & $\begin{array}{l}\text { Gender, Education, } \\
\text { Industry Experience }\end{array}$ & $\begin{array}{l}\text { Gender, Education, } \\
\text { Industry Experience }\end{array}$ \\
\hline Adj $R^{2}$ & .53 & .24 & .18 \\
\hline
\end{tabular}


This seeming paradox indicated that our simple model of production in recruiting firms was not accurate. While IT seemed to help individual workers bring more revenue to the firm, it was not simply speeding up their work. Further interviews revealed that employees often vary the number of projects they work on at a time such that workers' revenues are a function not only of how fast they work, but also of how much they multitask.

In our revised production model, employees work on projects whose number and duration determine total dollar "bookings" (contracts landed) and "billings" (contracts executed) revenue. If we consider white collar workers to be managing queued tasks, each with distinct start and stop points, we can measure the relationship between IT, information flows, and intermediate measures of output. In particular, data on project multitasking, and start and stop times over the sample period, index the rate at which projects are completed. These relationships are depicted in Figure 2.

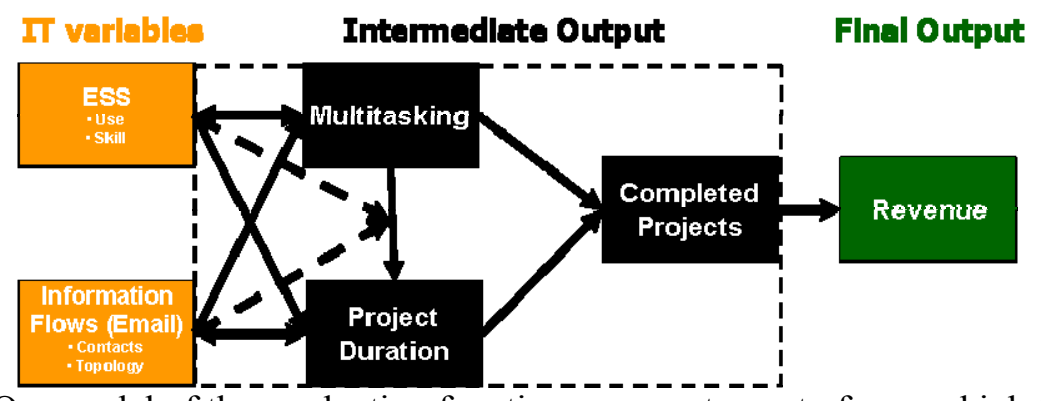

Figure 2. Our model of the production function represents a set of queued job tasks. The influence of IT and Information Flows can then be examined at the task level.

An aggregate model of production activity can be specified as in equation (1). This specification resembles that of Ichniowski, Shaw \& Prennushi (1997), and increment to $\mathrm{R}^{2}$, PE and Box-Cox tests indicate this additive form is preferred to a multiplicative Cobb-Douglas specification.

$$
\text { (1) } \quad Q_{i}=\alpha+\boldsymbol{\beta} \mathbf{H}_{i}+\boldsymbol{\gamma} \mathbf{X}_{i}+\boldsymbol{\delta} \mathbf{Y}_{i}+\varepsilon_{i}
$$

The determinants of output $\left(Q_{i}\right)$ in eq. (1) include dummy variables $\left(\boldsymbol{H}_{\boldsymbol{i}}\right)$ for the job level of individual workers; human capital $\left(\boldsymbol{X}_{\boldsymbol{i}}\right)$ reflected in recruiters' age, gender, educational attainment and years of ex- 
perience; IT and information flow variables $\left(\boldsymbol{Y}_{i}\right)$; constant $(\alpha)$ and error terms. ${ }^{6}$ In different models, $Q_{i}$ represents revenues, completed projects, or the number of simultaneous projects -- depending on the hypothesis. In contrast to earlier work, IT capital and non-IT capital are constant across all observations (i.e. recruiters) and are thus included in the constant term. Instead, the IT variables of interest pertain to IT skill and use of the technology, not merely its presence. In another contrast to traditional IT-productivity research, we include intermediate performance measures (e.g. multitasking, project duration) to estimate steps of the production process separately.

\subsection{Project Level Multitasking}

We developed project-level and individual-level measures of multitasking based on the multitasking profiles of each individual employee over every day of the five year time span of the study. A multitasking profile characterizes the projects an employee is engaged in during any given day, including not only the number of simultaneous contracts assigned to an employee, but also their relative share of project effort, the job types of the projects (e.g. the job classes of the projects and the cities in which they are based), and the dollar value of each project for the firm. With these data we constructed an individual multitasking measure weighted for effort share, and a team level multitasking measure tracking the average number of other projects a project team is working on during a focal project again weighted by assigned effort shares. Figure 3 displays a multitasking profile for one employee during the period $9 / 05 / 2002$ to $11 / 26 / 2002$.

\footnotetext{
${ }^{6} i$ indexes either projects or individuals depending on the analysis. Output per unit time is measured at the individual level. But, project outcomes are a result of joint, not individual effort. For project-level outcomes, we therefore analyze and measure teamlevel variables of interest.
} 


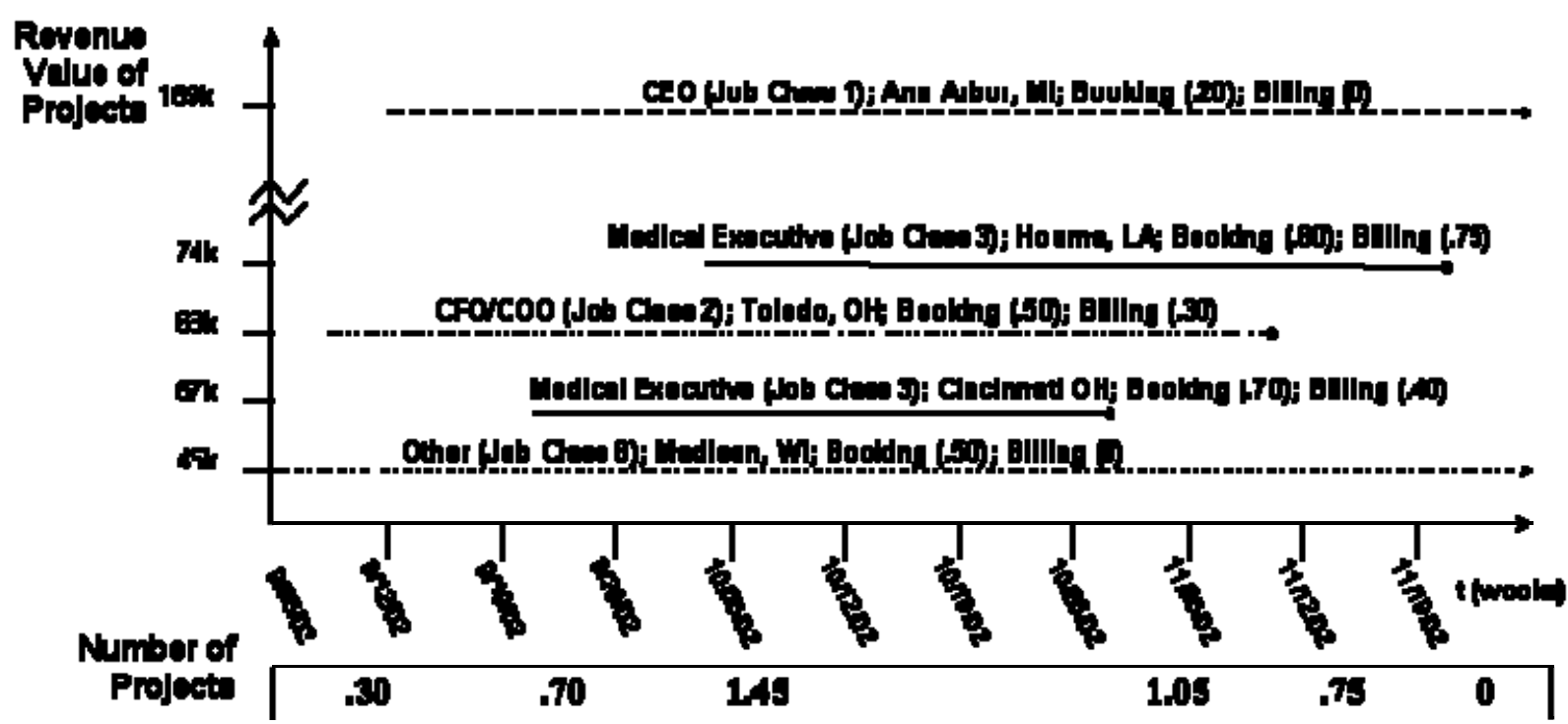

Figure 3. Multitasking Profile of Employee \#102 (9/05/2002 - 11/26/2002). A Multitasking Profile displays all of an employee's ongoing projects during a particular period; each project's job class and city; and the level of attention given by the employee to booking (Booking $\%$ ) and executing (Billing \%) each project. The graphic below the profile displays the employee's effort share weighted number of projects over time.

\subsection{A Model of Project Duration}

To test whether IT, information flows and the level of multitasking are related to the speed with which teams execute projects, we developed a parsimonious model of project completion rate. As the dataset contains right censored data, ${ }^{7}$ ordinary least squares can produce biased and inconsistent results of rate analyses (Tuma \& Hannan 1984). We therefore use a hazard rate model of the likelihood of a project completing on a given day, conditional on it not having been completed earlier. We employ a Cox proportional hazards model specification, formalized in equation (2), to estimate the relationships between IT use, information flows and the completion rate of projects:

$$
R(t)=r(t)^{b} e^{\beta X}
$$

where $R(t)$ represents the project completion rate, $t$ is project time in the risk set, and $r(t)^{b}$ the baseline completion rate. The effects of independent variables are specified in the exponential power, where $\beta$ is a vector of estimated coefficients and $X$ is a vector of independent variables. The coefficients in this model have a straightforward interpretation: $\beta$ represents the percent increase or decrease in the project 
completion rate associated with a one unit increase in the independent variable. ${ }^{8}$ Coefficients greater than 1 represent an increase in the project completion rate (equal to $\beta-1$ ); coefficients less than 1 represent a decrease (equal to $1-\beta$ ).

\subsection{Alternate Hypotheses and Control Variables}

Based on our interviews, we posit six broad factors that could influence our dependent variables besides the independent variables of interest:

Characteristics of Individual Recruiters. We included controls for traditional demographic and human capital variables (e.g. age, gender, level of education, industry experience and managerial level) to control for observable differences related to worker education, skill and experience. We also utilize fixed effects specifications to control for unobserved heterogeneity across individual recruiters.

Team Size. Adding more labor to a project may speed up work or slow it down depending on tradeoffs between the added complexity of a larger team and the output contribution of additional labor. We controlled for these effects by including a variable for the size of each team.

Job Type. Certain positions may be easier or harder to fill. Firms might, for instance, demand that a new CEO be named quickly. Senior executives also have more experience with recruiters and with job mobility. To control for the effect of Job Type, we include a dummy variable for the eight job classes the firm recognizes in its own records. ${ }^{9}$ We also control for Task Characteristics, measured by survey responses about the routineness and interdependence of tasks, for similar reasons.

City Characteristics. Crime rates, weather conditions, the cost of living and other city characteristics may increase or decrease the attractiveness of a position for candidates and may therefore influence contract completion due to placement difficulty. To control for these factors we collected data on the 768

\footnotetext{
${ }^{7}$ This reflects projects that did not complete during the observation window.

${ }^{8}$ Specification tests reveal no significant duration dependence in our explanatory variables, and the proportional hazards assumption is shown to be valid using both statistical and graphical tests.

${ }^{9}$ The firm categorizes jobs by the following categories: CEO, COO, CIO, Medical Executive, Human Resources Executive, Business Development Executive and 'Other.' We also ran specifications controlling for sub-categories of 'Other' jobs clustered by their project descriptions, which returned similar results. We therefore retain the firm's original classification.
} 
cities in our sample from the web site Sperling's Best Places. ${ }^{10}$ Factor analysis revealed four underlying factors with significant results in our models: cost of living, crime rates (violent crime and property crime per capita), weather conditions (number of sunny days per annum) and commute time. We therefore included these controls in project-level analyses. ${ }^{11}$

Revenue Value. The market price of a project contains information about the project's difficulty, value, priority and the market-assessed quality of work. As such, we include the revenue value of projects to control for differences in projects' difficulty, priority, and quality.

Temporal Variation. In order to isolate relationships between work process variables, such as multitasking, and output variables, we paid particular attention to the impact of both seasonal and transitory temporal shocks to the relationships. In our data, business exhibits seasonal variation. For instance, business picks up sharply in January and declines steadily through the next eight months. Given this variation, the exogenous shock of increased demand for executive recruiting services could drive increases in both the amount of work employees take on (multitasking), and the revenues they generate. In this case, we could find a spurious correlation between multitasking and revenues driven by an exogenous pulse in demand for the firms' services. There could also be non-seasonal transitory shocks to demand in a given year or a given month of a given year. For this reason, we control for both seasonal and transitory variation in our data with dummy variables for year, month and year/month separately.

\section{Statistical Specifications}

We tested three specifications of the relationship between revenues, completed projects, multitasking and project duration: Feasible Generalized Least Squares (FGLS) and Fixed Effects specifications at the daily level, and an OLS specification for the year 2002 independently. As daily regressions displayed significant levels of serial correlation based on Durbin-Watson tests and heteroskedasticity based

\footnotetext{
${ }^{10} \mathrm{http}: / /$ www.bestplaces.net/

${ }^{11}$ We collected city level data on tax rates for sales, income and property, the aggregate cost of living, home ownership costs, rate of home appreciation, air quality, water quality, number of superfund sites near the city, physicians per capita, health care costs per capita, violent and property crime per capita, public education expenditures per capita, average student to teacher ratio, an index of ultraviolet radiation levels, risk indices for earthquakes, tornadoes and hurricanes, average number of sunny, cloudy, and rainy days per year, average number of days below freezing per year and average commute time to work.
} 
on Breush-Pagan tests, we modeled these data in FGLS specifications using within-panel corrections for both heteroskedasticity and autocorrelation. The error term was modeled with autocorrelation diminishing uniformly over time: $\varepsilon_{t}=\rho \varepsilon_{t-1}+u_{t}$. We then examined OLS estimates of the relationships between our independent variables and multitasking at the project-level, with controls for job class, temporal variation and a variable indexing right censored project data. Finally, we employed a Maximum Likelihood specification to test the Cox proportional hazards models of project completion. We have reported standard errors according to the White correction (White 1980) for regressions that violated the assumption of no heteroskedasticity at the 5\% level. As project outcomes may cluster on groups of project team members, we report robust standard errors clustered by project team. ${ }^{12}$

\section{Results}

\subsection{Drivers of Production}

We determined through interviews that, in our setting, the key driver of production is the number of projects completed per unit time. As recruiting teams complete projects, they generate revenue for the firm. Our model of the production process therefore hypothesizes that a key intermediate variable in the 'black box' is completed projects, shown in Figure 2: Completed Projects $\rightarrow$ Revenues.

\footnotetext{
${ }^{12}$ Clustered robust standard errors treat each project team as a super-observation for part of its contribution to the variance estimate (e.g. $\varepsilon_{c i}=\eta_{c}+v_{c i}$, where $\eta_{c}$ is a group effect and $v_{c i}$ the idiosyncratic error). They are robust to correlations within the observations of each group, but are never fully efficient. They represent conservative estimates of standard errors that are particularly conservative in our data because team members expend varying levels of effort across projects, such that teams with similar composition have relatively independent share weighted values of team participation.
} 


\begin{tabular}{|c|c|c|c|c|c|}
\hline \multicolumn{6}{|c|}{$\begin{array}{l}\text { Table 3: Panel Data Estimates of the Drivers of Project Completion and } \\
\text { Revenue Generation }\end{array}$} \\
\hline Variables & Model 1 & Model 2 & Model 3 & Model 4 & Model 5 \\
\hline $\begin{array}{l}\text { Dependent } \\
\text { Variable: }\end{array}$ & Revenues & nRevenues & nRevenues & $\begin{array}{l}\text { nComp. } \\
\text { Projects }\end{array}$ & $\begin{array}{l}\text { nComp. } \\
\text { Projects }\end{array}$ \\
\hline Specification & $F G L S$ & $F G L S$ & Fixed Effects & $F G L S$ & Fixed Effects \\
\hline & Daily & Daily & Daily & Daily & Daily \\
\hline nEducation & $\begin{array}{c}2.10 \\
(1.62)\end{array}$ & $\begin{array}{c}.003 \\
(.003)\end{array}$ & & $\begin{array}{c}.001 \\
(.001)\end{array}$ & \\
\hline Gender & $\begin{array}{l}-.73 \\
(3.72)\end{array}$ & $\begin{array}{l}.001 \\
(.006)\end{array}$ & & $-.007 * *$ & \\
\hline Partner & $\begin{array}{l}654.17 * * * \\
\quad(11.42)\end{array}$ & $\begin{array}{l}1.041^{* * *} * \\
(.029)\end{array}$ & & $\begin{array}{l}.418 * * * \\
(.009)\end{array}$ & \\
\hline Consultant & $\begin{array}{l}521.14 * * * \\
(10.23)\end{array}$ & $\begin{array}{c}1.014 * * * \\
(.028)\end{array}$ & & $\begin{array}{l}.350 * * * \\
(.009)\end{array}$ & \\
\hline $\begin{array}{l}\text { Completed } \\
\text { Projects }\end{array}$ & $\begin{array}{c}2149.19 * * * \\
(43.41)\end{array}$ & & & & \\
\hline nMultitasking & & $\begin{array}{c}.140 * * * \\
(.010)\end{array}$ & $\begin{array}{c}.987 * * * \\
(.008)\end{array}$ & $\begin{array}{l}.360 * * * \\
(.007)\end{array}$ & $\begin{array}{c}.722 * * * \\
(.005)\end{array}$ \\
\hline nMultitasking & & $-.089 * * *$ & $-.272 * * *$ & $-.147 * * *$ & $-.146 * * *$ \\
\hline Squared & & $(.009)$ & $(.006)$ & $(.006)$ & $(.004)$ \\
\hline nDuration & & $\begin{array}{c}-.174 * * * \\
(.004)\end{array}$ & $\begin{array}{c}-.152 * * * \\
(.003)\end{array}$ & $\begin{array}{c}-.087 * * * \\
(.003)\end{array}$ & $\begin{array}{c}-.133 * * * \\
(.002)\end{array}$ \\
\hline Time Controls & Month, Year & Month, Year & Month, Year & Month, Year & Month, Year \\
\hline $\begin{array}{l}\text { Log } \\
\text { Likelihood }\end{array}$ & -370966.8 & 152093.6 & - & 133227.3 & - \\
\hline $\mathrm{X}^{2}(\mathrm{~d} . \mathrm{f}) / \mathrm{F}(\mathrm{d} . \mathrm{f})$ & $\begin{array}{c}8976.9 * * * \\
(20)\end{array}$ & $\begin{array}{c}4045.32 * * * \\
(22)\end{array}$ & $\begin{array}{c}6836.79 * * * \\
(18)\end{array}$ & $\begin{array}{c}17285.69 * * * \\
(22)\end{array}$ & $\begin{array}{c}5035.76^{* * * *} \\
(18)\end{array}$ \\
\hline Observations & 78201 & 78201 & 100816 & 81824 & 104983 \\
\hline
\end{tabular}

$* * * \mathrm{p}<.001 ; * * \mathrm{p}<.05 ; * \mathrm{p}<.10$. "n"=Normalized Variable; Multitasking terms are effort share weighted.

We tested this hypothesis by examining the relationship between completed projects and revenue

generation per person per day over the five year period. The results in Table 3, Model 1 demonstrate strong support for our basic model. The number of completed projects per day is a strong driver of individual information worker revenue generation. The coefficient indicates that the individual worker's share of the revenue generated from a day's work on an (eventually) completed project is worth, on average, $\$ 2,149.19$ dollars per day for the firm.

We then tested the second fundamental hypothesis of our model: that both revenues and completed projects are driven by the number of projects an individual works on per unit time, and by the length of time it takes to finish projects on average. We examined the relationship between multitasking, average duration, revenues and completed projects in Models 2-5 in Table 3. The results demonstrate that 
more simultaneous projects and faster completion times (shorter duration) are associated with greater project completion and revenue generation per person per day. ${ }^{13}$

We also find that the relationship between multitasking and output is non-linear. The coefficient on the multitasking squared term is negative and significant - implying a concave relationship, such that more multitasking is associated with greater revenue generation and project output to a point, after which there are diminishing marginal returns, then negative returns to increased multitasking. We considered four possible explanations for this inverted-U shaped relationship, and let the data speak to which is the most likely.

Explanation 1: A Fundamental Tradeoff between Workload and Efficiency. Perhaps the most intuitive explanation is that a fundamental trade-off exists between workload and efficiency, such that multitasking beyond a certain point reduces productivity. This explanation fits with empirical evidence on the cognitive costs of multitasking. Multitasking behavior has been associated with cognitive switching costs that reduce task completion rates and increase task error rates in experimental settings (e.g. Rubenstein et. al. 2001). When employees juggle too many simultaneous projects, work gets backed up and productivity suffers. The situation is analogous to congestion and throughput processes for queued activities. For example, the throughput of cars on a highway increases as more cars join traffic, but is reduced by congestion after a certain level of traffic is exceeded. Our interviews corroborate this story. As the CIO of the firm put it: "Everyone can only deal with so many balls in the air. When someone gets 'too far in,' they lose touch. They can't tell one project from another."

Explanation 2: Project Portfolios Differ by Employee Type. Correlated differences between individual workers and their project portfolios could also be driving the inverted-U shaped relationship between multitasking and output. For example, it could be that new, inexperienced workers take on fewer and less valuable projects, while the most experienced consultants take on the largest number. These two clusters of project portfolios would explain the first and last third of the inverted-U. Filling out the graph,

\footnotetext{
${ }^{13}$ As the variables for multitasking and duration are normalized with mean $=0$ and s.d. $=1$, the coefficients represent the standard deviation variation in the dependent variable associated with a one standard deviation change in the independent variable.
} 
partners may reserve the most important and valuable projects for themselves and work on fewer projects than consultants. Explanation 2 is consistent with several theoretical perspectives. Partners' social and organizational power (e.g. Pfeffer 1981) could enable them to take on a relatively small number of high revenue value projects, creating a relationship between leisure (less multitasking) and revenues in the partner strata of our data. This explanation is also consistent with incentive theories of deferred compensation, where workers are underpaid during the early part of their careers (e.g. $[\mathrm{Pay}=\mathrm{f}($ revenues $)]<$ marginal revenue product) and paid more than their marginal revenue product later on (Lazear 1979).

Explanation 3: Unobserved Drivers of Multitasking and Output. There could also be unobservable drivers of both multitasking and output that create the inverted-U shaped relationship. For instance, the most productive workers could also spend time on other tasks we don't observe (like networking) that drive them to work on fewer projects simultaneously while producing more output. If these highly productive workers worked on slightly more projects than inexperienced new workers, but fewer projects than experienced workers who did not spend time on these unobserved tasks, an inverted-U shaped relationship between multitasking and output could be observed.

Explanation 4: Exogenous Temporal Variation. Clients may hire top management teams in groups, creating temporal clusters of contracts that are both few in number and high in revenue value. If this type of turnover happens seasonally - for example, near the beginning or end of the fiscal year - then temporal clusters of fewer high revenue value projects could create the inverted U-shaped relationship. Exogenous transitory shocks to client demand could also inspire ramping up of production, or large simultaneous layoffs in low revenue value positions. Given the right structure, it is possible that these temporal clusters could drive the inverted-U shaped relationship between multitasking and output.

Reconciling Explanations. While explanations 2-4 conform to theory and could explain the slope of this relationship at different levels of multitasking, our specifications suggest they are unlikely. In FGLS specifications, our controls for managerial level and industry experience go a long way toward holding constant variation driven by status, organizational power or career tenure. In addition, our estimates of the relationship between multitasking and output are robust to specifications controlling for un- 
observed heterogeneity across individuals, accounting for aspects of social and organizational power not captured by organizational level and tenure, for unobservable practices (e.g. networking) of highly productive workers, and for other characteristics of individual recruiters which could contribute to the shape of the relationship between multitasking and output. In addition, our controls for temporal variation (both seasonal variation and exogenous shocks to demand) discount explanations based on temporal clusters of projects of different types. As our quantitative and qualitative data discount explanations 2-4, we are drawn to interpret the results in Table 3 as evidence supporting explanation 1: that a fundamental tradeoff exists between workload and efficiency. ${ }^{14}$

\subsection{Relationships between IT, Information Flows and Multitasking}

To test whether IT use and skill, and properties of the flow of information in workers' email traffic are related to the intermediate output variables shown to drive production, we first tested the relationship between our IT and information flow variables and project-level multitasking. Our analysis included controls for team characteristics and job class, but not for city characteristics, which are potentially salient for project duration but should not influence how many projects teams work on. ${ }^{15,16}$

The coefficients in Table 4, Models 1 and 3 demonstrate that teams whose members were heavy multitaskers communicated with more people over email, and significantly fewer people over the phone. Since the variables have been normalized, they can be interpreted as follows: a one standard deviation increase in the number of email contacts is associated on average with a .30 standard deviation increase in the number of simultaneous projects the team is working on during the focal project (see Model 3). We also see from the coefficient in Model 2 that teams who use the ESS system more to gather information work on more projects simultaneously. ${ }^{17}$ As synchronous technology (i.e. telephone) reduces multitasking while asynchronous technology (i.e. email, and to a lesser extent, ESS) supports multitasking, a manager

\footnotetext{
${ }^{14}$ Since we have not controlled for all possible sources of endogeneity or identified equilibrium values of multitasking and output, the optimal levels of multitasking implied by our parameter estimates may not be precise optima in equilibrium.

${ }^{15}$ We also ran the same analysis controlling for the revenue value of the project, with no qualitative change in the coefficients.

${ }^{16}$ The models include a dummy variable for whether the project was right censored during the observation window.
} 
seeking to juggle more projects might favor information access patterns that do not require coordinated scheduling. We also tested the analogous relationships between workers' email traffic and their amount of multitasking. The results for both the levels and structure of information flows in teams' email are reported in Table 5, Models 1-6. ${ }^{18} 19$

\begin{tabular}{|c|c|c|c|}
\hline \multicolumn{4}{|c|}{ Table 4: OLS Analysis of the Impact of IT on Multitasking at the Project-level } \\
\hline & Model 1 & Model 2 & Model 3 \\
\hline & OLS-c & OLS-c & OLS-c \\
\hline Team Size & $.227 * *$ & $.285^{* *}$ & $.207^{*}$ \\
\hline I eam size & $(.090)$ & $(.110)$ & $(.115)$ \\
\hline Education & $.102 * *$ & .077 & $.101^{*}$ \\
\hline & $(.052)$ & $(.055)$ & $(.051)$ \\
\hline Industry Experience & $\begin{array}{l}-.002 \\
(.007)\end{array}$ & $\begin{array}{c}.001 \\
(.006)\end{array}$ & $\begin{array}{l}-.002 \\
(.007)\end{array}$ \\
\hline nF2F Contacts & $\begin{array}{l}.030 \\
(.036)\end{array}$ & & $\begin{array}{c}.038 \\
(.036)\end{array}$ \\
\hline nPhone Contacts & $-.224 * *$ & & $-.229 * *$ \\
\hline nirnone Contacts & $(.090)$ & & $(.088)$ \\
\hline nEmail Contacts & $\begin{array}{l}.320 * * * \\
(.091)\end{array}$ & & $\begin{array}{l}.305^{* * *} \\
(.093)\end{array}$ \\
\hline nESS Skill & & $\begin{array}{l}.036 \\
(.078)\end{array}$ & $\begin{array}{l}-.029 \\
(.081)\end{array}$ \\
\hline nESS Use & & $\begin{array}{l}.114^{*} \\
(.064)\end{array}$ & $\begin{array}{l}.061 \\
(.061)\end{array}$ \\
\hline Constant & $\begin{array}{l}-1.98^{*} \\
(1.121)\end{array}$ & $\begin{array}{l}-1.65 \\
(1.146)\end{array}$ & $\begin{array}{l}-1.90^{*} \\
(1.114)\end{array}$ \\
\hline Job Class Controls & YES & YES & YES \\
\hline Time Controls & Year & Year & Year \\
\hline Censor Dummy & YES & YES & YES \\
\hline $\begin{array}{l}\text { F Value } \\
\text { (d.f) }\end{array}$ & $\begin{array}{c}8.49^{* * *} \\
(19)\end{array}$ & $\begin{array}{c}7.90 * * * \\
(18)\end{array}$ & $\begin{array}{c}7.88^{* * * *} \\
(21)\end{array}$ \\
\hline $\mathrm{R}^{2}$ & .16 & .12 & .16 \\
\hline Obs. & 1372 & 1372 & 1372 \\
\hline
\end{tabular}

All four measures of communication levels demonstrate strongly that heavy multitaskers communicate more over email. These results strengthen and extend the result from the survey measure of email contacts reported in Table 4.

\footnotetext{
${ }^{17}$ The coefficient on ESS Skill is positive and significant when entered alone, but not when controlling for ESS Use. ESS Use is significant at $p<.001$ in the full model (Model 3) when standard errors are robust but not clustered by project team.

${ }^{18}$ The models include a dummy variable for whether the project was right censored during the observation window. Estimates of information flow variables using non-clustered standard errors are all significant at $p<.001$.

${ }^{19}$ Variables that are highly collinear are entered separately into the regressions.
} 


\begin{tabular}{|c|c|c|c|c|c|c|}
\hline \multicolumn{7}{|c|}{$\begin{array}{l}\text { Table 5: OLS Analysis of Relationship Between Information Flows \& nMultitasking at the } \\
\text { Project-level ("n" = Normalized Variable) }\end{array}$} \\
\hline Variables & Model 1 & Model 2 & Model 3 & Model 4 & Model 5 & Model 6 \\
\hline \multirow[t]{2}{*}{ Dependent Variable } & \multicolumn{6}{|c|}{ Multitasking } \\
\hline & OLS-c & OLS-c & OLS-c & OLS-c & OLS-c & OLS-c \\
\hline \multicolumn{7}{|l|}{ Controls } \\
\hline Team Size & $\begin{array}{l}.223 * * * \\
(.069)\end{array}$ & $\begin{array}{l}.278^{* * *} \\
(.074)\end{array}$ & $\begin{array}{l}.221 * * \\
(.071)\end{array}$ & $\begin{array}{c}.226 * * * \\
(.068)\end{array}$ & $\begin{array}{l}.211^{* *} \\
(.076)\end{array}$ & $\begin{array}{l}.210^{* *} \\
(.066)\end{array}$ \\
\hline Yrs Education & $\begin{array}{l}.090^{*} \\
(.046)\end{array}$ & $\begin{array}{l}.085 \\
(.051)\end{array}$ & $\begin{array}{l}.079 \\
(.048)\end{array}$ & $\begin{array}{l}.091^{* *} \\
(.044)\end{array}$ & $\begin{array}{l}.084^{*} \\
(.048)\end{array}$ & $\begin{array}{l}.087 * * \\
(.042)\end{array}$ \\
\hline Industry Experience & $\begin{array}{l}.006 \\
(.007)\end{array}$ & $\begin{array}{l}-.002 \\
(.006)\end{array}$ & $\begin{array}{l}.006 \\
(.007)\end{array}$ & $\begin{array}{l}.007 \\
(.006)\end{array}$ & $\begin{array}{l}.003 \\
(.006)\end{array}$ & $\begin{array}{l}.003 \\
(.005)\end{array}$ \\
\hline \multicolumn{7}{|l|}{$\begin{array}{l}\text { Information Flow Level } \\
\& \text { Structure }\end{array}$} \\
\hline nTotal Emails & $\begin{array}{l}.320 * * * \\
(.067)\end{array}$ & & & & & $\begin{array}{l}.266^{* *} \\
(.104)\end{array}$ \\
\hline nNetwork Size & & $\begin{array}{l}.304^{* * *} \\
(.068)\end{array}$ & & & & \\
\hline nIn Degree & & & $\begin{array}{c}.301 * * * \\
(.068)\end{array}$ & & & \\
\hline nOut Degree & & & & $\begin{array}{l}.361 * * * \\
(.060)\end{array}$ & & \\
\hline nBetweenness & & & & & $\begin{array}{c}.307 * * * \\
(.060)\end{array}$ & $\begin{array}{l}.126^{*} \\
(.076)\end{array}$ \\
\hline $\begin{array}{l}\text { nConstraint } \\
\text { (1-Structural Holes) }\end{array}$ & & & & & $\begin{array}{l}-.134^{*} \\
(.071)\end{array}$ & $\begin{array}{c}-.181^{* *} \\
(.090)\end{array}$ \\
\hline Constant & $\begin{array}{c}-2.128 * * \\
(1.035)\end{array}$ & $\begin{array}{l}-2.125^{*} \\
(1.093)\end{array}$ & $\begin{array}{l}-1.870^{*} \\
(1.056)\end{array}$ & $\begin{array}{c}-2.230 * * \\
(.995)\end{array}$ & $\begin{array}{l}-1.79^{*} \\
(1.082)\end{array}$ & $\begin{array}{l}-.196^{*} \\
(1.002)\end{array}$ \\
\hline Job Class Controls? & YES & YES & YES & YES & YES & YES \\
\hline Temporal Controls: & Year & Year & Year & Year & Year & Year \\
\hline Censor Dummy? & YES & YES & YES & YES & YES & YES \\
\hline $\begin{array}{l}\text { F Value } \\
\text { (d.f) }\end{array}$ & $\begin{array}{c}9.63 * * * \\
(17)\end{array}$ & $\begin{array}{l}8.73^{* * *} \\
(17)\end{array}$ & $\begin{array}{l}9.29 * * * \\
(17)\end{array}$ & $\begin{array}{c}10.60 * * * \\
(17)\end{array}$ & $\begin{array}{l}9.97 * * * \\
(18)\end{array}$ & $\begin{array}{l}10.03 * * * \\
(19)\end{array}$ \\
\hline $\mathrm{R}^{2}$ & .20 & .18 & .19 & .23 & .20 & .24 \\
\hline Observations & 1372 & 1372 & 1372 & 1372 & 1372 & 1372 \\
\hline$* * * \mathrm{p}<.001 ; * * \mathrm{p}<.05 ; * \mathrm{p}<$ & 0. OLS-c $=$ & obust Clust & I Standard & rrors $(\mathrm{n}=$ & Clusters) & \\
\hline
\end{tabular}

ated with greater betweenness centrality - a proxy for the probability of being privy to a given piece of information flowing through the communication network of the firm. Heavy multitaskers are in the 'thick' of the flow of information and are likely to be 'in between' a larger number of pairs of other employees in terms of their communication structure. In day-to-day terms, it pays to be a communications middleman. Peripheral individuals, with lower information flows, show fewer projects per unit time. Similarly, employees with 'redundant contacts' multitask less. The negative coefficient on the constraint variable shows that those entangled in closed networks (networks whose members are all closely tied to- 
gether) work on fewer projects simultaneously. To untangle constrained social networks, organizations can diversify team assignments and job rotations. Both the level and the structure of information flows correspond strongly with multitasking behavior and structural parameters remain significant even when controlling for total email volume in Model $6 .^{20}$

These results demonstrate a strong correspondence between multitasking and the structure and level of email traffic. However, unobserved characteristics of project assignment may simultaneously drive multitasking and IT use. For example, it could be that multitasking is used more for simpler projects that are more readily accomplished via email. If so we may observe a correlation between multitasking and email use due to the nature of project assignment. To address these concerns, we examined the most likely sources of endogeneity in detail. We found that although simpler, lower revenue projects exhibited more multitasking (Revenue: $\beta=-644 ; \mathrm{t}=2.27$ ), project revenue was associated with less total email $(\beta$ $=-4288.35 ; \mathrm{t}=2.61)$ and with less database use $(\beta=-.112 ; \mathrm{t}=3.36)$, discounting the possibility that simpler projects simultaneously drive more multitasking and more email and database use. ${ }^{21}$ We also find email and database use are associated with greater multitasking when controlling for project type and revenue value (see Table 4). Although project assignment may be non-random in our setting, it does not explain relationships between IT use, email and multitasking.

\subsection{Relationships between IT, Information Flows, Multitasking and Project Duration}

To test the relationships between multitasking, IT, information flows and project duration, we estimated the hazard rate model of project completion time. Our specification tests the relationship between explanatory variables and projects' instantaneous transition rate - a measure of the likelihood of project completion at time $t$, conditional on the project not having completed before $t$. Table 6 shows the analysis

\footnotetext{
${ }^{20}$ It seems intuitive that employees working on more projects at once need to be aware of more lines of communication and information, and thus appear in these structural positions. However, we cannot make causal claims about these results. Heavy multitaskers may seek more information and position themselves in the thick of information flows, or highly central employees may be chosen to conduct more tasks, or may chose to conduct more tasks on their own. Nevertheless, information flows are associated with the multitasking behavior of information workers in our data.

${ }^{21}$ While projects in the medical field do exhibit more multitasking, total email use and the number of email contacts is fairly constant across project categories. This discounts the hypothesis that project assignment simultaneously drives IT use and multitasking, and is supported by analyses of IT use and multitasking that control for project type and revenue value.
} 
of the relationship between IT, multitasking and project completion rates, controlling for job type, task characteristics, and city characteristics.

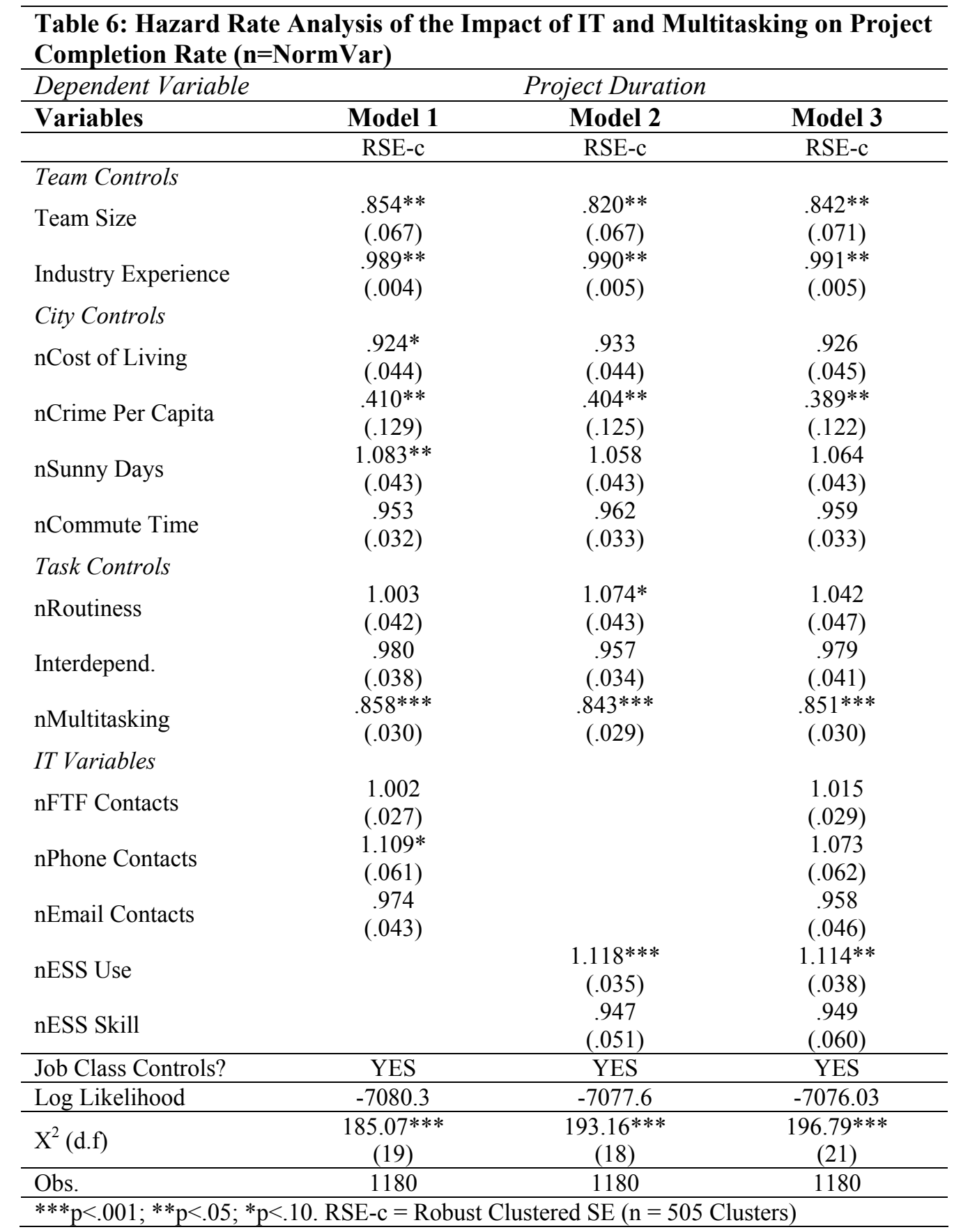

Multitasking is strongly associated with slower completion rates. Teams with a one standard de-

viation increase in project-level multitasking (approximately 2.8 additional projects) complete about $15 \%$ fewer projects per month. These results corroborate our interpretation of the drivers of the inverted-U shaped relationship between multitasking and output. Teams that multitask more take longer to finish pro- 
jects - a result consistent with a loss of efficiency at high levels of multitasking. Holding the level of multitasking constant, teams using the ESS to gather more information (S.D. $=15 \%$ ) complete projects on average $11 \%$ faster, and teams that use the phone more also execute projects faster. These results are a departure from our simple model of the impact of IT on project duration which did not control for the level of multitasking, indicating the analytical value of our more comprehensive model. ${ }^{22}$

Our analyses of the impact of multitasking and IT use on the speed of work demonstrate two key findings: First, multitasking slows work, explaining a possible mechanism driving the inverted-U shaped relationship between multitasking and output. Second, IT use shifts production out, increasing output at all levels of multitasking by enabling greater workloads without a corresponding loss of efficiency. ${ }^{23}$

We also analyzed how information flows and multitasking correspond to project completion rates. ${ }^{24}$ All control variables and the multitasking variable display significant results of almost identical magnitude as reported in Table 6. However, none of the six information structure or flow variables (total emails, network size, in-degree, out-degree, betweenness and constraint) returned a significant parameter estimate. ${ }^{25}$ While the levels and structure of information flows predict the level of multitasking, they do not predict the speed with which projects are completed, controlling for multitasking. This contrasts with Hansen (2002), which did not control for multitasking.

The strong positive coefficient on ESS use, together with survey and interview data, provides useful managerial insight. Although ESS use speeds projects by $11 \%$, comfort with and ability to use these

\footnotetext{
${ }^{22}$ Team size and industry experience are associated with longer project duration and slower completion rates. Teams with more members may take longer to execute projects due to the added complexity of coordination, or firm may resort to 'throwing more labor at' difficult jobs or jobs that are taking longer to complete than expected. Controlling for team size therefore may also account for differences in project difficulty not picked up by controls for job type, task, and city characteristics. Industry experience also corresponds to longer project duration perhaps because less experienced employees receive less demanding work. Cost of living, crime rates, and greater commute times all reduce the project completion rate on average, meaning these characteristics may be less attractive to potential candidates, while good weather seems to boost the completion rate. Routine tasks consistently finish faster, and greater interdependence among team members is associated with slower completion rates.

${ }^{23}$ We found no convincing evidence of any interaction effect of multitasking and IT use on the project completion rate in separate analyses, indicating that IT use enables greater project completion per unit time at all levels of multitasking.

${ }^{24}$ Detailed results on "Hazard Rate Analysis of the Impact of Information Flows and Multitasking on Project Completion Rate" are omitted due to space constraints, but are available upon request from the authors.

${ }^{25}$ When we remove city controls, network variables predict faster project completions (total email $\beta=1.051 ; p<.10$, network size $\beta=1.068 ; p<.05$, in-degree $\beta=1.055 ; p<.10$, out-degree $\beta=1.061 ; p<.10$ ), suggesting interdependence between geographic distribution and social network attributes - a result we intend to explore in future research.
} 
tools decline with age (Spearman's $\rho=-.47, \mathrm{p}<.001$, Spearman's $\rho=-.31, \mathrm{p}<.02$ ). This suggests that targeted training in ESS use could speed project completions at the firm. Overall, as multitasking reduces the per project completion rate, productive information workers trade longer task duration per project for more tasks per unit time by working on multiple projects in parallel. Productive executives then offset multitasking delay costs by using information technology more heavily.

\section{Discussion and Conclusion}

To date, important advances in assessing IT value have used more sophisticated econometric methods or more comprehensive firm-level and plant-level data. In contrast, our research seeks to open two new frontiers: (1) detailed task-level evidence of information worker output, and (2) objective measures of information flows through social networks. This approach provides a higher resolution microscope with which to study organizational phenomena, revealing finer grained relationships than would be possible with any amount of firm, industry, or country-level data.

Three contributions result from this approach. First, we show that information work can, in fact, be measured. We identified a context with objective performance metrics, built tools to directly observe behaviors and information flows in email, and gathered independent data on project quality controls. Our analyses of these data produce precise estimates of the productivity of information workers. While information work has often defied measurement in the past, we found it remarkably quantifiable in this setting.

Second, we build and validate multitasking and hazard rate models of project completions at both individual and team levels. These models highlight intermediate production processes and directly explore the association between using technology, juggling more tasks, and the ability to complete tasks faster. In effect, we used better data to reveal the production function of information workers. We find that individual differences in IT use behaviors correspond with differences in performance. On average, workers using more asynchronous email and database tools handle substantially more projects simultaneously. In contrast, traditional synchronous communication modes such as phone calls correlate with less multitasking. Further, there were speed implications. People who multitasked heavily benefited from also 
using the ESS heavily to speed their work, enabling them to complete more projects per unit time. These results, together with the survey data, imply that targeted ESS training could improve speed and thus firm performance.

Finally, and perhaps most interestingly, when we apply social network analysis to our email data, we find that position and flow are critically important. Betweenness centrality shows a positive association with ability to multitask, as do in-degree, out-degree, and network size. Among information workers, it pays to be a communications middleman. Peripheral employees, outside the communication flow, work on fewer projects over time. The total volume of communication is also statistically significant as is the measure of constraint, demonstrating that constrained networks and redundant contacts correspond to less multitasking. An implication of these results for managers is that untangling social networks through strategic job rotation could lead to more efficient multitasking. Previous research demonstrates that managerial interventions such as new human resource management practices can in fact alter the social networks of employees and their work flow and interaction (Gant, Ichniowski \& Shaw 2002). Strikingly, we also find that richer information flows alone do not necessarily increase the speed with which individuals complete their projects. Central information brokers boost their productivity by multitasking more effectively rather than by working faster.

In sum, we find a substantial correspondence among information, technology, and output in this setting. It is not just having IT but how one uses it that predicts differences in performance. Tools and techniques developed during this research can be readily applied to other project-level information work involving email and databases including sales, consulting, law, medicine, software development, venture capital, banking, insurance, and architecture, among others. This portends a substantial improvement in our understanding of the relationship between information, technology, and value creation, and reveals important managerial implications related to organizational structure, team assignment, job rotation, IT use and training, and the management of organizational communication.

\section{Acknowledgments}


We are grateful to the National Science Foundation (Career Award IIS-9876233 and grant IIS-0085725), Intel Corporation, the Marvin Bower Fellowship, and the MIT Center for Digital Business for generous funding. We thank Abraham Evans-El, Jia Fazio, Saba Gul, Davy Kim, Jennifer Kwon and Jun Zhang for their remarkable and tireless research assistance, and Julie Hilden, and seminar participants at the NBER,

NYU, MIT, Georgia Tech, the Workshop on Information Systems and Economics for valuable comments.

\section{References}

Apte, U., Nath, H. 2004. "Size, structure and growth of the U.S. economy." Center for Management in the Information Economy, Business and Information Technologies Project (BIT) Working Paper.

Arrow, K.J. 1962. “The Economic Implications of Learning by Doing.” Rev. Econ. Stud. (29:3): 155-173.

Bartel, A., Ichniowski, C. \& Shaw, K. Forthcoming. "How does information technology affect productivity? Plant level comparisons of product innovation, process improvement and worker skills." Quarterly Journal of Economics: 1-39.

Barua, A., C. H. Kriebel, Mukhopadhyay, T. 1995. "Information technology and business value: An analytical and empirical investigation." Information Systems Research (6:1), March: 2-23.

Bernard, H.R., Killworth, P., \& Sailor, L. 1981. "Summary of research on informant accuracy in network data and the reverse small world problem." Connections, (4:2): 11-25.

Bharadwaj, A. S., S. G. Bharadwaj, Konsynski, B.R. 1999. "Information technology effects on firm performance as measured by Tobin's q." Management Science (45:7): 1008-1024.

Breusch, T., Pagan, A. 1979. "A simple test for heteroscedasticity and random coefficient variation." Econometrica (47:5), September, 1287-1294.

Brynjolfsson, E., Hitt, L. 1996. "Paradox lost? Firm-level evidence on the returns to information systems spending." Management Science (42:4), April, 541-558.

Brynjolfsson, E., Hitt, L. 2000. "Beyond computation: Information technology, organizational transformation and business performance." Journal of Economic Perspectives (14:4), Fall, 23-48.

Bulkley, N., Van Alstyne, M. 2005. "Why Information Should Influence Productivity” in Network Society: A Cross Cultural Perspective, Manuel Castells (Ed.), Edward Elgar, Northampton, MA, 145-173. 
Burt, R. 1992. Structural Holes: The Social Structure of Competition. Harvard Press, Cambridge, MA.

Coleman, J.S. 1988. "Social Capital in the Creation of Human Capital” Amer. Jrnl. Soc., (94): S95-S120.

Cyert, R.M., March, J.G. 1963. A Behavioral Theory of the Firm, Malden, MA, Blackwell Publishers.

David, P.A. 1990. "The Dynamo and the Computer: A Historical Perspective on the Modern Productivity Paradox." Amer. Econ. Rev. Papers and Proceedings (80:2), May, pp. 355-361.

Dewan, S., Kraemer, K. 2000. "Information technology and productivity: evidence from country-level data." Management Science (46:4), April, 548-562.

Freeman, L. 1979. "Centrality in social networks: Conceptual clarification.” Soc. Networks (1:3): 215-34.

Galbraith, J.R. 1973. Designing Complex Organizations. Reading, MA, Addison-Wesley.

Gant, J., Ichniowski, C., \& Shaw, K. 2002. "Social capital and organizational change in high-involvement and traditional work organizations." Journal of Economics and Management Strategy, 11(2): 289328.

Gargiulo, M., Benassi, M. 2000. "Trapped in your own net? Network cohesion, structural holes, and the adaptation of social capital." Organization Science (11:2), March-April, 183-196.

Granovetter, M. 1973. “The strength of weak ties.” American Journal of Sociology (78:6): 1360-1380.

Hansen, M. 1999. "The search-transfer problem: The role of weak ties in sharing knowledge across organization subunits." Admin. Sci. Quart. (44:1), March, 82-111.

Hansen, M. 2002. "Knowledge networks: Explaining effective knowledge sharing in multiunit companies." Organization Science (13:3), May/June, 232-248.

Hinds, P.J., Kiesler, S. 2002. Distributed Work. Cambridge, MA. MIT Press.

Ichniowski, C., K. Shaw, Prennushi, G. 1997. "The Effects of Human Resource Management Practices on Productivity: A Study of Steel Finishing Lines." Amer. Econ. Rev. (87:3): 291-313.

Jorgenson D., Stiroh, K. 2000. "US Economic Growth at the Industry Level." Amer. Econ. Rev. (90:2): $161-7$.

Lazear, E. 1979. “Why is there mandatory retirement?” J. Political Economy (87:6), 1261-1264. 
McAfee, A. 2002. "The impact of enterprise technology adoption on operational performance: An empirical investigation." Production and Operations Management Journal (11:1), Spring, 33-53.

Mukhopadhyay, T., R. Surendra, Srinivasan, K. 1997. "Information Technology Impact on Process Output and Quality." Management Science (43:12), December, 1645-1659.

Pfeffer, J. 1981. Power in Organizations, Pitman, Boston.

Podolny, J., Baron, J. 1997. "Resources and relationships: Social networks and mobility in the workplace." American Sociological Review (62:5), October, 673-693.

Reagans, R., Zuckerman, E. 2001. "Networks, diversity, and productivity: The social capital of corporate R\&D teams." Organization Science (12:4), July-August, 502-517.

Rubinstein, J., D. Meyer, Evans, E. 2001. "Executive Control of Cognitive Processes in Task Switching." Journal of Experimental Psychology: Human Perception and Performance (27:4): 763-797.

Stiglitz, J. 2000. "The Contributions of the Economics of Information to Twentieth Century Economics." Quarterly Journal of Economics (115:4), November, 1441-1478.

Szulanski, G. 1996. "Exploring internal stickiness: Impediments to the transfer of best practice within the firm." Strategic Management Journal (17), Winter, 27-43.

Tuma, N.B., Hannan, M.T. 1984. Social Dynamics: Models and Methods. Academic Press, New York. Van Alstyne, M. Zhang J. 2003. "EmailNet: A System for Automatically Mining Social Networks from Organizational Email Communication," NAACSOS.

von Hippel, E. 1998. "Economics of Product Development by Users: The Impact of "Sticky" Local Information" Management Science (44:5), May, 629-644.

White, H. 1980. “A heteroscedasticity-consistent covariance matrix estimator and a direct test for heteroscedasticity." Econometrica (48:4), May, 817-838. 


\begin{tabular}{|c|c|c|}
\hline \multicolumn{3}{|c|}{ Appendix A: Description of Variables and Data Sources } \\
\hline Variable & Source & Description \\
\hline \multicolumn{3}{|l|}{ Project Team Variables } \\
\hline Team Size & Accounting & Number of team members assigned to project. \\
\hline Age & Survey & Age of employees, Average age of team members. \\
\hline Yrs Education & Survey & Years of education, Average years of education of team members. \\
\hline Industry Experience & Survey & Years of industry experience, Average years of industry experience of team members. \\
\hline Multitasking & Accounting & $\begin{array}{l}\text { Share weighted number of simultaneous projects, weighted by the billing } \% \text { assignment of each employee to each } \\
\text { project. }\end{array}$ \\
\hline Project Duration (Days) & Accounting & Days from project start to project end. \\
\hline Project Revenue Value (\$) & Accounting & Revenue value of project. \\
\hline Team Interdependence & Survey & $\begin{array}{l}\text { 1-7: "My job tasks are highly interdependent with other people's tasks. I must often coordinate with other team } \\
\text { members." }\end{array}$ \\
\hline Task Routiness & Survey & 1-7: "My data requirements are highly routine. I could specify all I need on standard forms.” \\
\hline F2F Contacts & Survey & How many people do you communicate with on a typical day face to face? \\
\hline Phone Contacts & Survey & How many people do you communicate with on a typical day by phone? \\
\hline Email Contacts & Survey & How many people do you communicate with on a typical day by email? \\
\hline ESS (Database) Skill & Survey & $\begin{array}{l}\text { Combined: (1-7) "I am highly effective at using our in-house proprietary search tools. This means I know what } \\
\text { information they contain and can easily find, add, and modify the records I need." \& "I have control over the in- } \\
\text { formation I use; I can access and modify it at will." }\end{array}$ \\
\hline ESS (Database) Use (\%) & Survey & $\begin{array}{l}\text { "What proportion of your time do you spend gathering information from the internal database and external pro- } \\
\text { prietary databases?" }\end{array}$ \\
\hline Degree Centrality & Email & Number of ties to others. Row or column sums of adjacency matrix. \\
\hline In Degree & Email & Number of incoming ties to others. Column sums of adjacency matrix. \\
\hline Out Degree & Email & Number of outgoing ties to others. Row sums of adjacency matrix. \\
\hline Network Size & Email & Number of unique contacts linked to ego email, plus ego. \\
\hline Betweenness & Email & The percentage of all geodesic paths from neighbor to neighbor that pass through ego. \\
\hline Constraint & Email & Measures the extent to which ego's connections are to others who are connected to one another. (Burt 1992: 55) \\
\hline \multicolumn{3}{|r|}{ 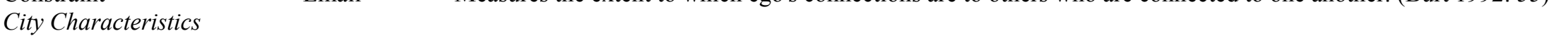 } \\
\hline Cost of Living & City Data & $\begin{array}{l}\text { The average cost of living in the following categories weighted as follows: Housing }(30 \%) \text {, food and groceries } \\
(15 \%) \text {, transportation }(10 \%) \text {, utilities }(6 \%) \text {, health care }(7 \%) \text {, miscellaneous - clothing, services and entertain- } \\
\text { ment }(32 \%) \text {. State and local taxes not included. }\end{array}$ \\
\hline Crime per Capita & City Data & Violent and property crime per capita. \\
\hline Sunny Days per Annum & City Data & Average number of sunny days per year. \\
\hline Commute Time & City Data & Average number of minutes to work one way. \\
\hline
\end{tabular}

